\title{
THE VALUE OF PROFESSIONAL CONVERSATION AS ILLUSTRATED BY A DISCUSSION ON PROFESSIONAL DEVELOPMENT
}

\author{
James Harrison and Perseville Mendoza
}

\section{INTRODUCTION}

The recognition of shared professional conversation has become a natural part of the facilitation practiced by James with his Master of Professional Practice students at Otago Polytechnic. This recognition resulted from two experiences. First, it came about by accident as he sought clarity from students on how their developing models of practice were becoming more coherent and providing the answers to the research problems they were addressing. Second, the subsequent sharing of his developing thinking for his own PhD with a professional colleague personally opened up many useful avenues of thinking, and James realised that the process not only helped his collegial relationship with Perseville, but also enhanced and staircased their comprehension of their respective fields of interest.

This paper attempts to explore the concept of professional conversation, as well as articulate its value as an important method of experiential learning and reflective practice. This is done by demonstrating how a conversation concerning professional development shows itself to be an exercise in reflective staircasing, whilst exhibiting an examination of our respective current models of learning. In comparing our models, we establish a foundation for further development. Much of what Perseville emphasises in this paper is borne out of the many conversations with James as facilitator, supporting the idea that professional conversation has a significant place in professional development.

The first part of the paper looks at two models which provided useful insight into the professional conversation process. These are an adaption of the Johari window concept and the experiential learning process. The second part proceeds with a comparison of our learning models and what we can draw from them professionally and personally. This is done by presenting our respective models, and then proceeding to specific areas in our conversation. The last part of the paper offers some conclusions, based around our reflections on the experience of engaging in a professional conversation.

\section{SOME GUIDING MODELS}

Professional conversation and collegiality have long been fundamental to professional colleagues in many fields(Andrews \& Lewis, 2007; Hord, 1997). Not only do they form the guiding principles of many professional bodies, they have formed an important pathway for more experienced professionals to mentor their new colleagues in the formation of their professional practice(Andrews \& Lewis, 2007; Schwille, 2008). References to this kind of process are many and varied and range from the Socratic approach to learning, to reviews of research by professional colleagues and its application to discourse(Grimshaw, 1989; Werth, 1981). However the perspective and process in which the professional conversation can be undertaken is less well developed and this is what is focussed on here. 
The Johari Window model of perception used here provides an interesting perspective on the benefit for such sharing. Note it combines the initial Johari Window (Saxena, 20 I5) concept of Duft, with a later model of cognition called the Dunning Kruger effect (Kruger \& Dunning, 1999).

The coloured slices shown in figure I represent:

- What a person knows s/he knows (blue, person I; yellow, person 2)

- What a person knows s/he does not know (red, person 1; pale blue, person 2)

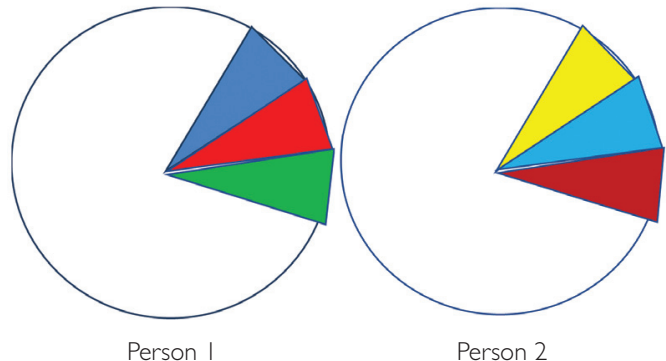

Figure I. Representation of Johari window perceptions of two people.

- What a person does not know s/he knows (green, person 1; brown person 2)

- The remainder of the picture is what the person does not know that s/he does not know.

For each person, these proportions in terms of the whole picture are roughly the same, and as the picture shows, the proportion stays the same if one person knows more than another.

As our individual knowledge grows, the proportion of what we do not know of which we are not aware grows in the same proportion, i.e. the more we know the less we know.

But when two people share with each other, there will be some things that one person knows that another does not know they do not know, and vice versa. Consequently, to share is to become aware of one's own lack of knowledge or to gain a perspective on one's own knowledge that one did not have before. The impact of this multiplies across a collegial group or community of practice in one field.

The model of experiential learning I (James) use is derived from an adaption of Dewey's model. Dewey's model of reflective thought and action is based on the Darwinian biological theory of adaption and evolution that arises from an organism finding that its habitual behaviour no longer works. He (Dewey, 1997) considers that there are two types of experience.

- Primary experience which remains largely unconscious and unknown unless it starts to create problems as described above;

- Secondary experience which is where the problem is reflected upon and the consequences used to create learning.

Elkjaer, (Illeris, 2009) describes Dewey's definition of experience to mean more like culture, in the sense that it is an ongoing interaction between a subject and their world. It is also linked to the future as well as the past. It can affect both subject and world. At the same time, it can be emotional and spiritual in nature as much as it might be an occurrence.

The area of learning addressed by the experiential learning process can be many things, including other models of practice, phenomena, and any form of change which is neither explained nor expected.

In terms of a professional conversation, the significance of the use of a cyclical iterative model of action and reflection on the object of discussion provides a relevant structure in which to situate and explore the respective perspectives of each participant's contribution. Each contribution is evidence that provides a new perception for the other and the ways in their perspective on the topic differs from one's own. Depending on the nature of the differences identified as well as the significance and the length of conversation, there may be opportunities to 
undertake several iterations of one's experiential cycle to explore and adjust one's respective understanding or to identify components that require further research. Each conversational contribution creates a cycle of practice that effectively staircases one's own understanding to potentially an enhanced outcome.

\section{OUR MODELS OF DEVELOPMENT AS THE BASIS OF OUR PROFESSIONAL CONVERSATION}

It should be noted that a key component of a professional conversation is the model of development that each participant uses in their field of expertise. The models described below are useful to compare because they have recently been derived by each author in their own postgraduate study and have led to findings that not only are seen as relevant to professional development, but to our own practice as facilitators with others. In our conversation, we consciously sought to reflect on our learning models for the purpose of staircasing our own understanding of professional development. Each of our models are described to provide the context for our professional conversation concerning their comparison.

\section{James Harrison}

The model of developmental practice described here arises from my $\mathrm{PhD}$ study which is currently being written up. However, some of the findings have previously been presented at international conferences in recent years and readers are referred to these papers for a more detailed description of their compilation: see Harrison (2017), and Harrison \& Soltani (20|8).

The model of developmental practice shown in Figure 2 bears close comparison to the model of experiential learning already described earlier when it was realised that the processes of problem solving, experiential learning and research shared very similar characteristics with each other (see Figure 3).

The concept of capability arises from the capability concept derived from the UK manifesto of Capability defined by the Royal Society of Arts and later work by Stephenson \& Yorke (1998). This defines capability as the ability to apply one's competence in new or more complex contexts. This led to my identification that

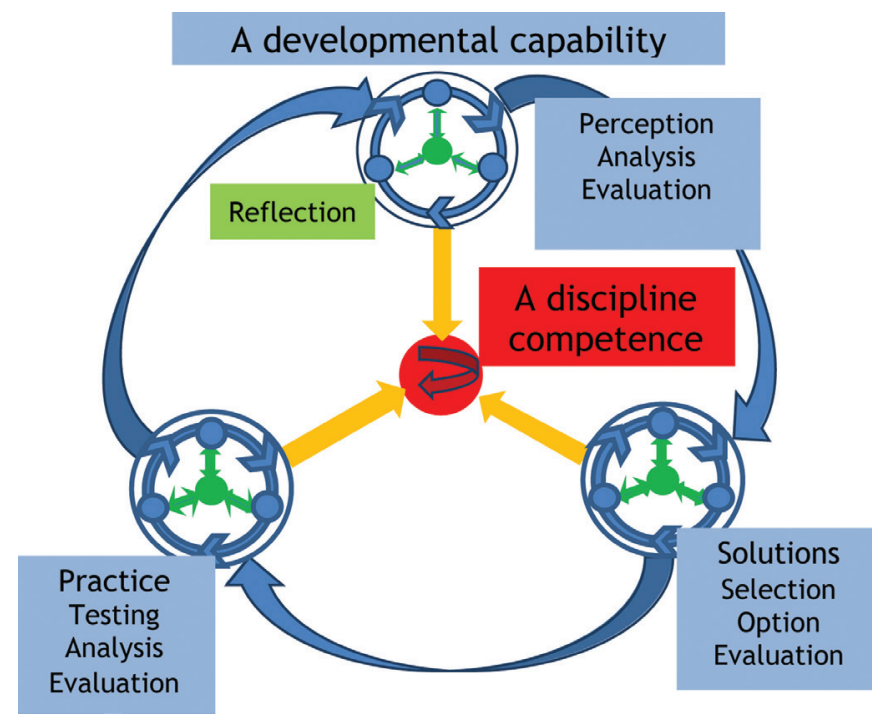

Figure 2. A model of developmental practice. capability could be defined as a cyclical iterative process.

The capability process begins with an identification stage in which something is identified that needs attention. This arises from ongoing application of discipline competence where an anomaly is detected between what is happening and the current practice of discipline competence. This could be a problem, something that needs to be researched or something that needs to be understood and could involve one or more of the capability development processes shown in Figure 2. 
Based on what is identified, the next stage is to determine what needs to be done to resolve the matter identified using or developing the models that form part of the discipline competence. These can either be process or theoretical models. Note that every stage of the capability process is informing and adding to the level or scope of disciplinary competence. What follows is then a practical stage of applying and working with the models to test their suitability, examine the findings arising and evaluating whether the matter is resolved or needs further work. This informs and adjusts the model of disciplinary competence at every stage of the development capability cycle.

If the matter needs further work, then another cycle of practice is undertaken. Importantly, all the above occurs in specific discipline contexts and should be understood and evaluated accordingly.

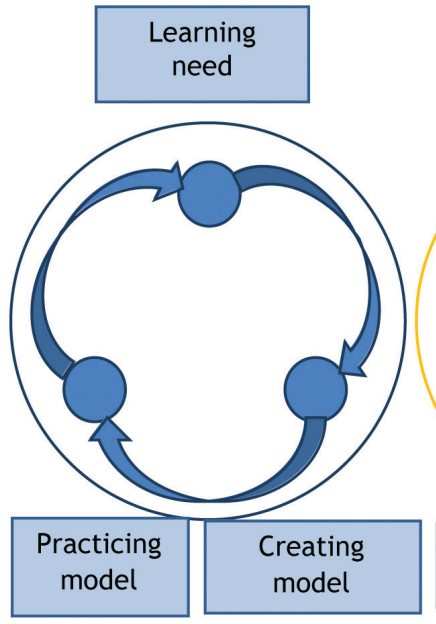

Experiential Learning
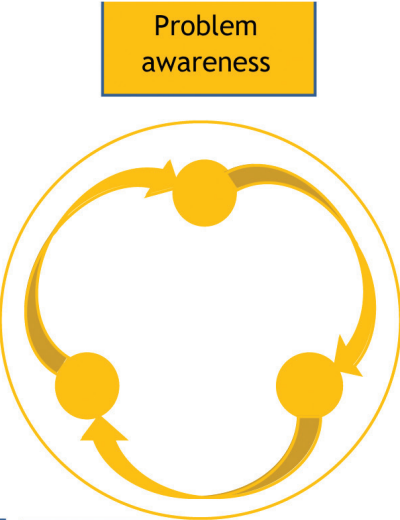

Testing

solution

Problem solving

\section{Devising} solution
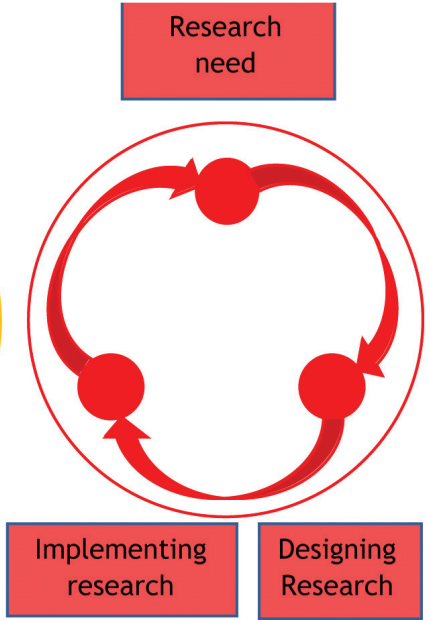

Designing

Research

Figure 3. The similarity between experiential learning, problem solving and research developmental capabilities.

Note that all of the stages of these developmental capabilities are making use of other processes or techniques which are cyclical, self-referential and iterative. At the same time, the main capability stages themselves may need to be adapted or improved to meet the needs of the issue being dealt with.

The significance of the iterative nature of this model is the ability for the discipline competence and developmental capability to grow with every new need or problem identified. Where an individual moves into another discipline field, the existing discipline competence is a starting point for a new pathway of development and progression. Hence, vocational practice using these developmental capability processes is being built upon and added to for the whole of one's life (see Figure 4).

The development of the discipline competence and the developmental capabilities can be undertaken simultaneously from the outset and throughout an education or training programme. The model lends itself to the application of problem based and project-based development processes in a progressive way culminating in independent demonstration and self-assessment of full integrated discipline competence and development capability practice as a summative programme outcome.

The significance of the developmental practice model shown in Figure 4 is that it not only reflects growth in capability and discipline competence, but it also shows a pathway through time and different disciplines in which an individual recognises where they have come from and where they are going. It can be considered a total quality management process for human performance and development. 


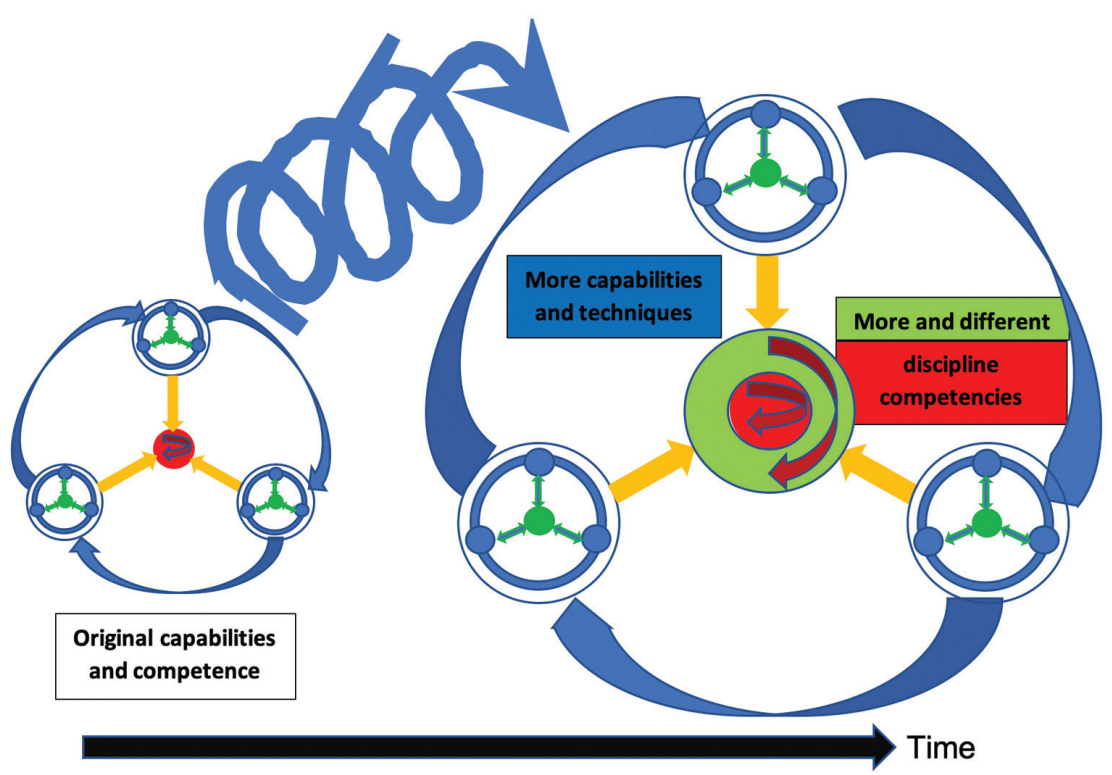

Figure 4. A model of developmental practice showing growth of competence and developmental capability through time and different contexts.

More importantly, the current state of professional practice and performance defined by competence is but a temporary state of output in the continuous lifelong development of capability. Much of contemporary performance and qualification definition is defined in terms of the former rather than the latter. This lack of comprehension and understanding of professional growth hinders both individuals and society at large in terms of individuals being able to adapt to new fields and disciplines seamlessly, and gives rise to capability barriers first articulated by Sen (1993).

\section{Perseville Mendoza}

The project of identifying and articulating my own learning process, and thereafter, illustrating it as a model of learning, came about in the pursuit of my Master of Professional Practice (MProfPrac). Though initially a project on critical thinking, the research evolved into a project on critical learning considering the strong relationship between learning and problem-solving.

The development of my model of learning is based on reflections involving several experiences both as student and teacher, specifically in learning martial arts and music, as well as learning and teaching philosophy. The experience of home-schooling my children also contributed to the views that I have about learning and teaching. From these reflections, I drew up a basic personal learning model, whereby the process of learning is driven by an underlying practice of reflection all throughout. After much reflection borne out of conversations with my facilitator, I have come to the realisation that whether in martial arts, music, or philosophy, my learning has been informed by an engagement with a problem, followed by an attempt to resolve and understand both the problem and the solution, and then a refinement of the solution that should be applicable to other similar scenarios (Figure 6).

This model is not particularly complex nor ground-breaking. Yet, its distinctive characteristic is found in the thinking process itself, whereby each stage is comprised of both convergent and divergent modes of thinking. The model attempts to articulate possible combinations of these two modalities in order to express the fundamental relationship between critical thinking and reflection, and how such a combination leads to critical learning. 


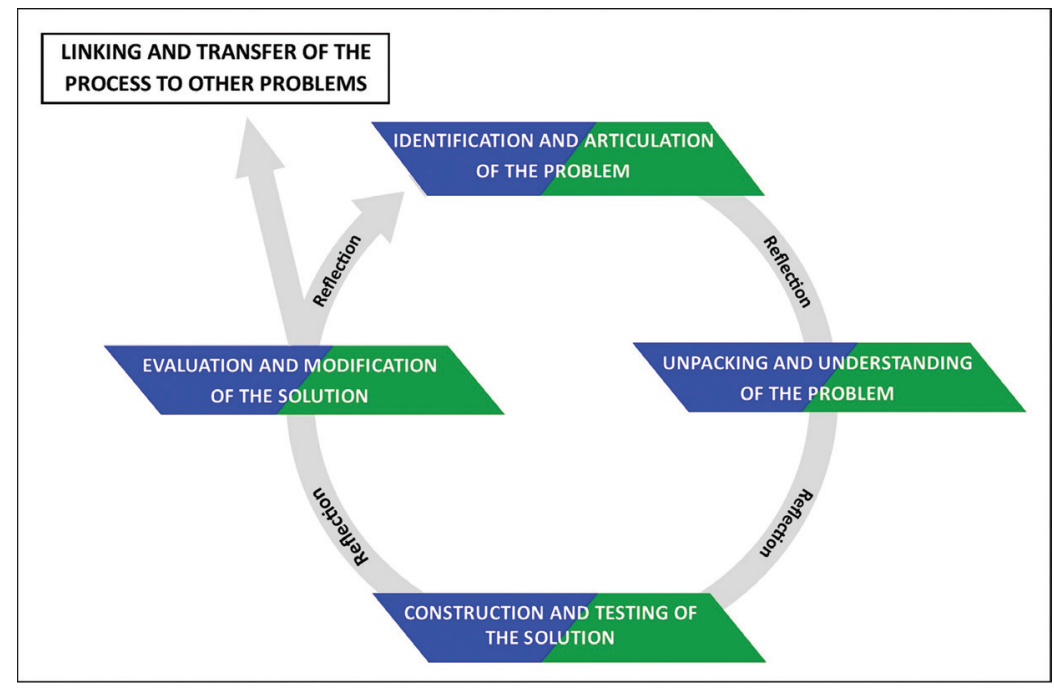

Figure 5. A Learning/Problem-solving model.

In the process of visualising this relationship, I matched the two processes in order to see how the entire combined process would possibly come together. I ended up with a diagram where the two processes may be performed simultaneously:

The idea behind these thinking modalities is that on one hand, analysis allows a learner to exercise focused thinking, thereby helping a learner to see conceptual foundations. Reflection, on the other hand, because it is not necessarily bound to and by strict logical relations, allows for a broader, more creative perspective on thought and conceptual linkages. It is a mode of thinking that looks at alternatives and possibilities. Learning thus becomes possible at the level of reflection. Yet critical thinking plays an important role in giving a learner a grasp of the abstract concepts. By having a process that places these modalities side-by-side, I believe that a particular process of critical learning may be identified, and a transferable method may ultimately be employed towards an enhancement of thinking and learning capabilities.

Figure 6, therefore, is a pictorial representation of how these thinking modalities operate within a learning/problemsolving process. Note how the stages of identification and articulation, unpacking and understanding, construction and testing, and evaluation and modification are all paired in accordance with the convergent-divergent modes.

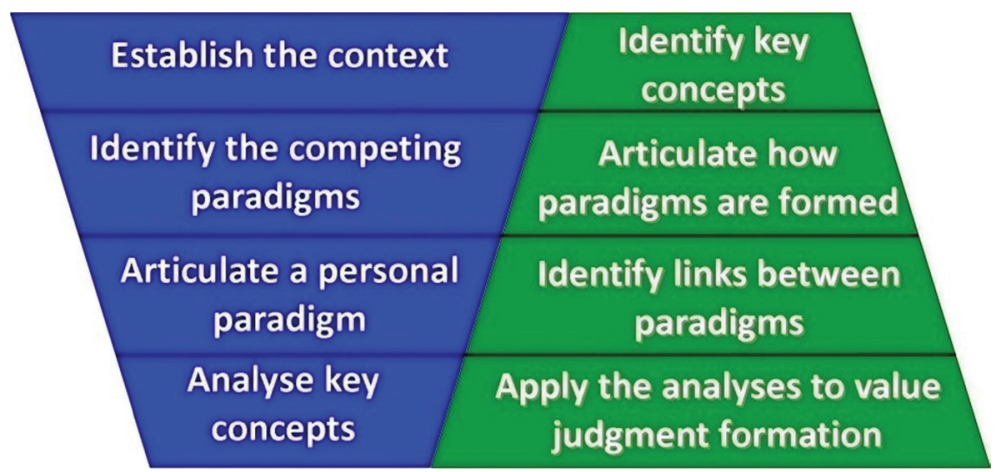

Figure 6. Pictorial representation of convergent-divergent processes. 
Drawing on seemingly unrelated experiences as an academic, a musician, and as a martial artist, the role and importance of problem/dilemma-scenarios in learning slowly became more apparent. In both academia and martial arts for example, any and all types of information or "knowledge" become relevant only in the context of the problematic situations that they address. By turning this framework into a learning principle, the learning process becomes more defined and focused, theoretically leading to a more efficient model of learning and education. Works, such as those of Adair (2007), Mak, Mak, \& Mak (2009), and Bell (2014), point to the centrality of problemscenarios in learning. For instance, it is a problem-scenario that paves the way for the scientific method in the first place, and if research follows the same process as scientific inquiry in particular and learning in general, then these are all driven by problem-based learning. It becomes apparent that learning is about meaning-making, and the path to making sense of the world is paved by problems, or more specifically, finding solutions to problems. When we are served with any type of information, it becomes relevant only when it answers the question, Why do I need to know $x$ ? But notice that this question is simply another way of asking, What is $x$ a solution to? Therefore, learning happens when our experiences make sense or are meaningful, and they become meaningful when they are solutions or answers to problem-scenarios. Interestingly enough, Mak et al. (2009) offer a shorter version of the scientific method in this form: Observation, Hypothesis, and Experiment, which essentially corresponds to the fundamental learning cycle of Kolb (1984). This implies that, true enough, the scientific method is essentially framed by the same process as that of learning.

It is argued here that such significance can only be acquired in the context of problem-solving. In other words, any research is to be interpreted in terms of how it is a solution to something. Raw data or information is out there, true enough, but for such information to gain meaning to a researcher, it must fit into and help make sense of something larger. Quite simply, it is the sense of a gap in one's construction of reality that pushes learning forward whether in everyday life, in the scientific method, or in research.

\section{KEY OBSERVATIONS FROMTHIS MODEL-COMPARING EXERCISE}

The models were similar in that both found linkages between the processes of learning and the processes of problem solving. The processes were cyclical, reflecting the seemingly natural tendency to learn in terms of cycles. They could be repeated iteratively to improve the results because it appears that self-assessment is built into the process. A significant subprocess of reflection formed an integral part of every stage of the process cycle. In sum, what learning entails in any context is that it is about process.

One difference between the two models lies in the scope of what these respective models are trying to represent. Whereas James' model of professional practice is necessarily more advanced and highly developed in terms of representing a universal pattern of professional development, Perseville's model is located in the micro-process of learning that is applicable to the level of disciplinal/professional, as well as personal, learning. It is more akin to what James identifies as sub processes in his model of professional practice and development.

The primary focus of Perseville's model of learning is problem solving stemming from a combination of convergent and divergent thinking. What is interesting is that the function of his convergent-divergent thinking modes is analogous to James' model's incorporation of the "global" (what could be viewed as a universal pattern of development) and "local" (sub processes) dimensions of professional development. This is noteworthy, because in seeking to draw up pictorial representations of professional development and learning, we separately came up with analogous perspectives incorporated into our models. The implication of this congruence is the apparent universal nature of learning as cyclical and iterative, despite the differing language that was used in those respective models.

Another point of contrast is that James' model included the concept of a research process as a problem without an immediate answer, as well as reflection integrating both convergent and divergent processes. Convergent reflection was seen as a conscious process of open questioning, whereas Perseville went further and defined this as a form of critical thinking. In divergent thinking, James made use of the concept of linking useful ideas together from intuition 
and "aha" moments of awareness, whereas Perseville used divergent modes of thinking. This is a good example of where such differences have led onto further useful reflection and expansion of the respective perspectives concerning an understanding of their purpose and the sub processes which led to that.

Out of these observations, the conversation focused on two key perspectives that pertain to the value and practice of our learning processes, and how the latter translates into our professional practice in the academe. The following section presents those perspectives according to the flow of the dialogue, with the aim of demonstrating the power of engaging in a professional conversation as it leads to powerful insights and reflections.

\section{VALUING AND PRACTISING OUR LEARNING PROCESSES}

In terms of valuing and practising our learning practices, we both found that their application in our facilitation or tutoring roles encouraged us to not simply observe their effect on our students, but also to reflect on their benefit to ourselves and the ways by which we might improve our own use of these processes.

\section{James}

I emphasised that my role as a facilitator meant that I was trying to build on the student's concept of their own stage of development and that the focus of my process was to get them to develop their own model of practice and development, and that their realisation of their own successful practice was more important than the extent to which it used my ideas as it built their confidence and learning autonomy.

A useful technique I often share with my students is to make use of analogies and metaphors which have more general applicability than simply talking specifics. One example I often make use of in developing a research concept or identifying their future professional practice is the metaphor of painting a picture. That is, they start by envisaging the subject or purpose of the picture and then identify through a developmental process, the players and the context as well as the process by which it is to be realised. At each stage of the process they are focused on a particular subset of the big picture. But each part of the picture is being worked on all the time, each having their own sub cycle of activity and then the whole picture being reviewed frequently to asses which part needed more attention.

\section{Perseville}

In our conversation, I had related how talking about the value of being aware of our learning process reminded me of a recent mountain biking episode that I had with my eldest son. Whilst my son is still relatively new to the sport, he is nevertheless advanced enough to provide me with instruction. Armed with an awareness of my learning process, I tested out how I might go about learning a technical skill such as mountain biking. I found that, as with most areas of epistemological inquiry, learning happens at a quicker rate when framed within a problem-solving context. In this instance, the confirmation came from my son who was ecstatic at the rate that I was learning the necessary skills to navigate through the bike trail. Yet it is important to remember that consistency is a factor in determining whether the learner actually "learnt" something or not.

From this experience, I shared with James how an awareness of my learning process allows for a congruence between the professional and the personal in terms of learning and professional development. My profession in the academe involves engaging others in a process of learning, which I also could test and apply onto myself, in a variety of areas. From my perspective, this awareness could serve as a foundation for a method of learning that starts with an identification of a gap in our perception of the world, and then seeking avenues that could serve as solutions because they fill in those perceptual gaps in our constructivist view of reality. 


\section{WHAT AND HOW WE WISH TO DEVELOP OUR STUDENTS}

\section{James}

The importance of a student being able to develop their own learning and practice capability cannot be underestimated. This is primarily for identifying a coherent process for themselves, but then making use of the process leading to useful outcomes that others recognise and acknowledge. This in turn provides the motivation to continue to develop further.

\section{Perseville}

I had mentioned how my model of learning is framed by problem-solving. What this means is that for me, learning is initiated by a motivation to get a better picture of the world. I think it is no accident that James' technique of using the metaphor of painting a picture is an effective approach, because it is consistent with problem-solving. This problem-solving-as-learning framework gives new insight into what a problem-based approach to learning implies. Rather than simply referring to the practice of using problems for its own sake, it is about using the experience of problem-scenarios to initiate the search for solutions that may complete the picture of the world. This is a powerful approach because it is experiential learning, that is, it stems from and appeals to the learner's experience.

In tutorials, I usually pose problem-scenarios to help learners tease out key concepts on their own, with varying degrees of guidance from me as the facilitator of the discussion. However, I also seek to help them develop the ability to ask the key questions themselves, in order to propel or initiate a learning process. What this implies is that if learning is problem-solving, then to have the ability to pose a problem is tantamount to being aware of one's learning process. In this sense, to be capable of learning is to have a grasp of the process itself.

\section{JOINT CONCLUSIONS ARISING FROMTHE PROFESSIONAL CONVERSATION}

There are several ideas and conclusions stemming from our conversation that we find worth pursuing in the future. First, both models represented a state of our own development and understanding with the discipline, and each offered something of equal validity to others working with their models. In this field, a constructivist epistemological perspective was an aid to our exploration, our development and a contribution to the community of practice in learning and facilitation. No one model has the complete answer. Each provides insights and opportunities for further enhancement for individuals and groups operating in a social space of practice. The efficacy of these models lay not with their outcomes but in the processes which could be continually improved over a lifetime of practice.

Second, the recognition of the need for a universality of problem solving in the same way as research provides a rich area of further research and development. It appears that the lack of universality in the description of problem solving methods means that its recognition of transferability is not currently the same as it is for research and as a result its significance as a developmental capability is not yet as recognisable. The idea of a shared language of learning is the notion of a universal language of problem-solving, whereby "language" is understood as a metaphor for the process of problem-solving. Looking at James' model, perhaps its value can be seen in terms of how it is universally applicable as a model of professional development. Linking the latter idea to problem-solving as meaningmaking in a professional setting, James' model sets the stage for the universality of process itself. In an academic context, research is also arguably problem-solving in the sense that it is about meaning-making, therefore paving the way for the view that these are all essentially the same process.

Third, Perseville's cultural background in Eastern learning offers an interesting field of exploration to identify other contributions to enhance models of personal and collective development. It becomes meaningful to explore the possibility of a shared language of learning, whilst comparing and contrasting some Eastern and Western frameworks. 
Fourth, the ethics of developing human potential and capability, especially from Amartya Sen's perspective (Sen, 1993), is also worth exploring especially with regard to language as a contextual limitation. Considering that academic institutions are primarily aimed at developing learner capability, what happens when these institutions unintentionally become the source of limitations through the nature of language being used? What ought to be the nature of upskilling in its fundamental sense, if not the tying in of the academic with real world problems?

Fifth, and perhaps one central conclusion that can be derived from this exercise, is that the value of professional conversations lies in the process by which this dialogue is engaged in. Its collaborative nature, as well as the comparing and contrasting of approaches, employs feedback in a most effective form. The result is a better picture of reality that stems from the confirmation of one another's ideas and perspectives. Yet such an exposure to the ideas of others also allows for the potential refinement of one's own views, which goes to the heart of the learning. In both our cases, recognised professional discussions of this nature helped illuminate areas of our models that were worth further investigation. Moreover, as our own profession was that of helping others to learn, we were very aware that being conscious of using conceptual models like this with our students offered significant and ongoing opportunities of self-improvement. Recognising the importance of professional conversations, therefore, gives this practice an important place in professional development.

James Harrison BSc Hons, MBA has enjoyed an extensive set of careers in industry, the civil service, and Higher Education both here and the United Kingdom. This has included responsibility for the professional development of several hundred scientists, engineers and business professionals within a capital electronics company of GEC Marconi, one of four civil servants leading the UK vocational qualification changes in the late 20th century, deriving qualifications for the NZ Electronic Industry and delivering senior academic roles in the NZ tertiary sector. He has for the past 4 years supported mature domestic and international students undertaking bachelor and master's work based learning qualifications at Capable NZ. He is currently completing a part time doctorate researching professional development at Victoria University Melbourne.

Perseville Mendoza earned his PhD, MA, and BA degrees in Philosophy from the University of the Philippines where he is an assistant professor. He completed a Master of Professional Practice from Otago Polytechnic, researching the relationship between critical learning and problem-solving. As an academic for the past 19 years, he has taught philosophy from the undergraduate to the postgraduate levels. Currently, he handles applied ethics papers at the AUT City Campus, New Zealand. 


\section{REFERENCES}

Adair, J. E. (2007). Decision making and problem solving strategies (Vol. 9). Kogan Page Publishers.

Andrews, D. \& Lewis, M. (2007). Transforming practice from within: The power of the professional learning community. Professional Learning Communities: Divergence, Depth and Dilemmas, I32-147.

Bell, J. (20|4). Doing Your Research Project: A guide for first-time researchers. McGraw-Hill Education (UK).

Dewey, J. (1997). How we think. Courier Corporation.

Grimshaw, A. D. (1989). Collegial discourse: Professional conversation among peers (Vol. 32). Praeger Pub Text.

Harrison, J. (2017). The emerging links between Learning Capability, Experiential Learning and Research: Political implications for Higher Education. Unpublished article. Retrieved from https://www.academia.edu/35773882/

Harrison, J. \& Soltani, D. B. (2018). Development of a contemporary model of personal vocational practice. Unpublished article. Retrieved from https://www.academia.edu/35773882/ Hord, S. M. (1997). Professional learning communities: Communities of continuous inquiry and improvement.

Illeris, K. (2009). Contemporary theories of learning: learning theorists... in their own words. Routledge.

Kolb, D. A. (1984). Experiential learning: Experience as the source of learning and development.

Kruger, J. \& Dunning, D. (1999). Unskilled and unaware of it: how difficulties in recognizing one's own incompetence lead to inflated self-assessments. Journal of Personality and Social Psychology, 77(6), 1121.

Mak, D. K., Mak, A. T. \& Mak, A. B. (2009). Solving everyday problems with the scientific method: thinking like a scientist. World Scientific.

Saxena, P. (20I5). JOHARIWINDOW: An effective model for improving interpersonal communication and managerial effectiveness. SIT Journal of Management, 5(2), I34-146.

Schwille, S. A. (2008). The professional practice of mentoring. American Journal of Education, I I 5(1), $139-167$.

Sen, A. (1993). Capability and well-being. The quality of life (Vol. 30). Oxford University Press.

Stephenson, J. \& Yorke, M. (1998). Capability and quality in higher education. Kogan Page.

Werth, P. (198I). Conversation and Discourse: Structure and Interpretation. Croom Helm. 